\title{
Commentary: Total arterial revascularization: Is it for everyone?
}

\author{
Harold L. Lazar, MD
}

\author{
From the Division of Cardiac Surgery, Boston University School of Medicine, Boston, Mass. \\ Disclosures: Author has nothing to disclose with regard to commercial support. \\ Received for publication Dec 17, 2018; accepted for publication Dec 17, 2018; available ahead of print January \\ $29,2019$. \\ Address for reprints: Harold L. Lazar, MD, Division of Cardiac Surgery, Boston University School of Medicine, \\ 80 E Concord St, Boston, MA 02118 (E-mail: Harold.1.lazar@gmail.com). \\ J Thorac Cardiovasc Surg 2019;157:2237-9 \\ $0022-5223 / \$ 36.00$ \\ Copyright (C) 2018 by The American Association for Thoracic Surgery \\ https://doi.org/10.1016/j.jtcvs.2018.12.054
}

Tavilla and colleagues ${ }^{1}$ present their 20 -year outcomes utilizing 3 in situ grafts to achieve total arterial revascularization (TAR) in 201 patients undergoing coronary artery bypass graft (CABG) surgery from 1992 to 2002. The majority of patients $(78 \%)$ received a left internal thoracic artery (ITA) to the left anterior descending artery, a right ITA to the left circumflex system via the transverse sinus, and a right gastroepiploic artery to the right coronary artery (RCA). No patient was lost to follow-up and $82 \%$ of patients had more than 15 years of follow-up. At 20 years, survival was $63.5 \%$, the incidence of myocardial infarction was $7.8 \%$, the need for a percutaneous coronary intervention was $9.3 \%$, and the incidence of reoperation $\mathrm{CABG}$ was $7.0 \%$. Cardiac deaths occurred in $12.9 \%$ and deaths from other causes occurred in $15.2 \%$. Based on their results, Tavilla and colleagues ${ }^{1}$ conclude that "cardiac surgeons should embrace the application of total arterial grafting to further reduce the risks of long-term cardiac events, especially during the second decade after CABG." However, before we embrace the concept of TAR for all of our patients, the limitations of this study should be acknowledged.

This was a select group of patients: the average age was 53 years, only $4.5 \%$ were women, $10.6 \%$ had diabetes, and only $6.5 \%$ had a poor ejection fraction. The authors excluded patients with chronic obstructive pulmonary disease, severe or poorly controlled insulin-dependent diabetes, and cardiogenic shock and "preferentially used TAR in patients with a life expectancy of more than 10 years." No graft patency data were provided and most importantly, there was no control group; that is, a series of patients with both arterial and venous grafts. Nevertheless, the authors have shown us what can be accomplished with TAR in properly selected patients-but is TAR for everyone?

There is now an increased emphasis for the use of multiple arterial grafting (MAG) and TAR to increase long-term survival following CABG. The use of MAG is now recommended in the Society of Thoracic Surgeons practice guidelines for $\mathrm{CABG}^{2}$ and TAR is now a class IIB recommendation for patients younger than age 60 years with few comorbidities in the American guidelines and a class IIA recommendation for

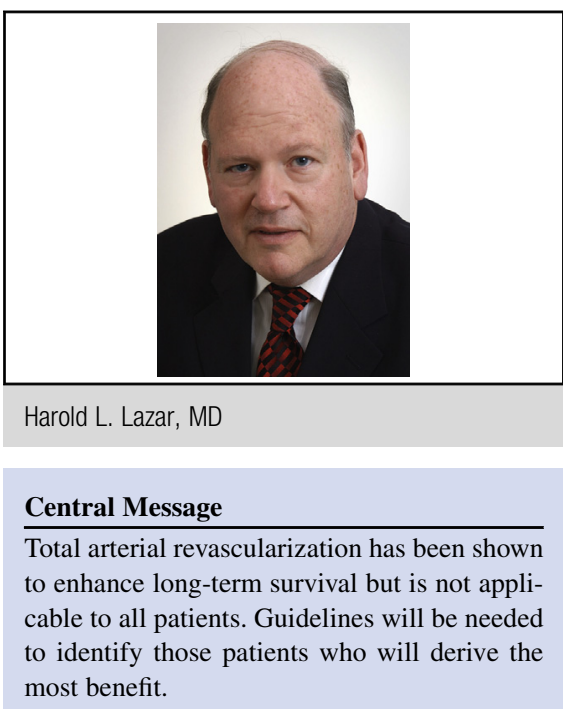

See Article page 2228.

patients with a reasonable life expectancy in the European guidelines. ${ }^{3}$ It has been strongly suggested that bilateral ITA grafting be made a quality metric for $\mathrm{CABG}$ reimbursement. Despite these recommendations, the most recent Society of Thoracic Surgeons National Database indicates that a single ITA graft is used in $89.4 \%$ of CABG patients, MAG in $10.6 \%$, and bilateral ITA in only $4.9 \%{ }^{4}$ Why then, are surgeons reluctant to perform MAG and TAR? The reasons are multifactorial. The increased time needed to harvest multiple arterial grafts increases operating time. Although the increased incidence of sternal wound infections with bilateral ITA grafting is small, the morbidity and mortality is high; especially in high-risk patients. Furthermore, these data are now publicly reported. Perhaps the most important factor involves concerns about the data supporting MAG and TAR. Most of the data supporting increased survival with MAG are derived from retrospective, nonrandomized studies and meta-analyses with variability in propensity matching and selection bias. ${ }^{5,6}$ The patients are younger with few comorbidities. All surgeons are aware that good patients make good surgeons. These studies lack data on graft patency, the complexity of the coronary anatomy (eg, Synergy Between Percutaneous Coronary Intervention With Taxus and Cardiac Surgery [SYNTAX] scores) and the quality of the target vessels. There is no mention of the cause of death. A recent study from Denmark showed that the highest incidence of cardiovascular deaths occurred 
within the first year following $\mathrm{CABG}^{7}{ }^{7}$ At a mean follow-up of 7.4 years, $52 \%$ of deaths were from noncardiac causes. Advanced age, chronic renal failure, and chronic obstructive pulmonary disease were risk factors for cardiovascular mortality 1 to 7 years following CABG. In the Arterial Revascularization Trial, ${ }^{8}$ cardiovascular deaths were responsible for $59 \%$ of all deaths, but fell to $38 \%$ during the period from 1 to 5 years following surgery. Without graft patency data, it is difficult to determine the mechanisms for the improved long-term survival seen with MAG and TAR. It has been suggested that arterial grafting may better protect the distal native coronary vessel from the progression of atherosclerosis. ${ }^{9}$ Data on secondary prevention and control of risk factors and compliance with medical therapy is not provided in these studies. It may well be that these younger, lower-risk patients undergoing MAG and TAR are more aggressively treated with statins and antiplatelet agents and undergo better risk modification, including cessation of smoking, diet, and weight control, and are more likely to be enrolled in exercise and fitness programs.

Do we need better trials and more data to determine the role of MAG and TAR in CABG surgery? Randomized trials would need to recruit a large number of patients to be adequately powered, would require recruitment from multiple centers, and would need to be adequately funded. Because most trials show a survival difference between single ITA versus bilateral ITA only after 10 years, a longer time period may be necessary to show the superiority of TAR. These trials would take too long to provide the important data needed to make changes in the practice of CABG surgery. There are currently data to help guide surgeons to determine which patients may benefit the most from MAG and TAR, and in whom these techniques should be avoided based on preoperative risk profiles. Several factors should be evaluated when considering MAG or TAR.

\section{AGE}

Lytle and colleagues ${ }^{10}$ first demonstrated that improved survival after bilateral ITA grafting first becomes evident in the second postoperative decade. Patients selected for MAG and TAR should have a life expectancy of at least 5 to 10 years from the time of their CABG. Although bilateral ITA grafting should not be contraindicated based solely on advanced age, several studies have shown no increased survival with bilateral ITA versus single ITA in patients older than age 70 years, ${ }^{11,12}$ and in some series, older than age 65 years. ${ }^{13,14}$ Routine use of bilateral ITA may not offer any significant survival benefit to septuagenarians with significant comorbidities or octogenarians because of their limited life expectancy. ${ }^{15}$

\section{COMORBIDITIES}

In the study by Tavilla and colleagues, ${ }^{1}$ obesity, a history of smoking, and chronic obstructive pulmonary disease were the highest risk factors for long-term mortality following TAR. In addition, patients with end-stage renal disease; peripheral vascular disease; uncontrolled, severe diabetes mellitus; and underlying malignancies also have a limited life expectancy following CABG. These patients are unlikely to benefit from MAG or TAR.

\section{INABILITY TO ACHIEVE COMPLETE REVASCULARIZATION}

Schwann and colleagues ${ }^{16}$ studied the effect of the completeness of revascularization on long-term survival following CABG and whether MAG would have any influence on survival. Incomplete revascularization was associated with decreased late survival despite the use of MAG. Incomplete revascularization in patients undergoing CABG may be a surrogate for irreversibly damaged myocardium. Target vessels may be ungraftable due to small caliber, diffuse disease and because they supply nonviable myocardium. Therefore, MAG and TAR are unlikely to improve long-term survival in those patients in whom complete revascularization is not possible.

\section{COMPLEXITY OF NATIVE CORONARY ARTERY DISEASE}

In addition to achieving complete revascularization, the extent of native disease may also determine the benefits of long-term survival with MAG. Schwann and colleagues ${ }^{17}$ found that although increasing the number of arterial grafts was associated with incrementally improved 15 -year survival, it was only significant for patients with 3 -vessel disease. There was no survival benefit beyond a single arterial graft in patients with 2-vessel disease.

\section{PATIENTS AT RISK FOR STERNAL COMPLICATIONS}

MAG and TAR should not be performed in patients in whom there is concern for sternal wound complications. These include women with obesity and diabetes, patients who are heavy smokers with chronic obstructive pulmonary disease, patients with chest wall deformities, patients in whom wound healing may be an issue due to osteoporosis or malnutrition due to decreased serum albumin levels, and in those patients who are immobile or in whom sternal precautions cannot be instituted.

\section{DEGREE OF DISTAL TARGET STENOSIS}

ITA grafting has decreased patency in patients with $<70 \%$ stenoses. Radial artery graft patency is best in patients with $>80 \%$ stenoses. This may limit the use of TAR in some patients. This is especially true for patients with RCA disease. Luthra and colleagues ${ }^{18}$ found no survival advantage to using an arterial graft versus a saphenous vein graft to the RCA after a follow-up of 7 years and Grau and colleagues ${ }^{19}$ found no survival advantage after 14 years. 
Mukherjee and colleagues ${ }^{20}$ found that vein graft patency was actually better than patency for arterial grafts in the RCA territory. This most likely represents the decreased patency seen when arterial grafts are used to bypass lesions with $<70 \%$ stenoses. Tavilla and colleagues ${ }^{1}$ used the right gastroepiploic artery to revascularize the RCA system. However, this involves entering the abdomen, which can lead to postoperative ileus, and may become an issue for patients who develop malignancies and require gastric or pancreatic resections. ${ }^{21,22}$ In patients with $>80$ stenoses, the radial artery may be a better arterial conduit.

MAG and TAR will continue to evolve as important strategies to enhance long-term survival and reduce major cardiovascular events after CABG. However, it will not be applicable to all patients. Guidelines will need to be developed to identify those patients who will derive the greatest benefits from these techniques.

\section{References}

1. Tavilla G, Bruggemans EF, Putter H. Twenty-year outcomes of coronary artery bypass grafting utilizing 3 in situ arterial grafts. J Thorac Cardiovasc Surg. 2019;157:2228-36.

2. Aldea GS, Bakaeen FG, Pal J, Fremes S, Head SJ, Sabik J, et al. The Society of Thoracic Surgeons clinical practice guidelines on arterial conduits for coronary artery bypass grafting. Ann Thorac Surg. 2016;101:801-9.

3. Kolh P, Kurlansky P, Cremer J, Lawson J, Siepe M, Fremes S. Transatlantic editorial: a comparison between European and North American guidelines on myocardial revascularization. J Thorac Cardiovasc Surg. 2016;152:304-16.

4. Schwann TA, Habib RH, Wallace A, Shahian DM, O'Brien S, Jacobs JP, et al. Operative outcomes of multiple arterial versus single-arterial coronary bypass grafting. Ann Thorac Surg. 2018;105:1109-20.

5. Gaudino M, Puskas JD, DiFranco A, Ohmes LB, Iammaccone M, Barbero U, et al. Three arterial grafts improve late survival: a meta-analysis of propensitymatched studies. Circulation. 2017;135:1036-44.

6. Yanagawa B, Verma S, Mazire A, Tam DY, Juni P, Puskas JD, et al. Impact of total arterial revascularization on long term survival: a systemic review and metaanalysis of 130,305 patients. Int J Cardiol. 2017;233:29-36.

7. Butt JH, Sorenson R, Back C, Olsen PS, Thorensteinsson K, TorpPederson $\mathrm{C}$, et al. Short and long term cause of death in patients undergoing isolated CABG: a nationwide cohort study. J Thorac Cardiovasc Surg. 2018; 156:54-60.
8. Taggart DP, Altman DG, Gray AM, Lees B, Gerry S, Benedetto U, et al. Arterial revascularization trial: randomized trial of bilateral versus single internalthoracic artery grafts. $N$ Engl J Med. 2016;375:2540-9.

9. Dimitrova KR, Hoffman DM, Geller CM. Arterial grafts protect the native coronary vessels from atherosclerotic disease progression. Ann Thorac Surg. 2012;94:475-81.

10. Lytle BW, Blackstone EH, Sabik JF, Houghtaling P, Loop FD, Cosgrove DM. The effect of bilateral internal thoracic artery grafting on survival during 20 postoperative years. Ann Thorac Surg. 2004;78:2005-12.

11. DeSimone JP, Malenka DJ, Weldner PW, Iribane A, Leavitt BJ, McCullough JN, et al. Coronary revascularization with single vs bilateral mammary arteries: is it time to change? Ann Thorac Surg. 2018;106:466-72.

12. Kieser TM, Lewin AM, Graham MM, Martin BJ, Galbraith DD, Rabi EM, et al. Outcomes associated with bilateral internal thoracic artery grafting: the importance of age. Ann Thorac Surg. 2011;92:1269-75.

13. Mohammadi S, Dagenais F, Voisine P. Lessons learned from the use of 1977 in situ bilateral internal mammary arteries: a retrospective study. J Cardiothorac Surg. 2014;9:158-63.

14. Kurlansky PA, Traad EA, Dorman MJ, Galbut DL, Ebra G. Bilateral versus single internal thoracic artery grafting in the elderly: long term survival benefit. Ann Thorac Surg. 2015;100:1374-81.

15. Gatti G, Dell'Angela L, Benussi B. Bilateral internal thoracic artery grafting in octogenarians: where are the benefits? Heart Vessels. 2016;31:702-12.

16. Schwann TA, Yammine MB, El-Hage-Sleiman AKM, Engoren MC Bonnell MR, Habib RH. The effect of completeness or revascularization during coronary artery bypass grafting with single versus multiple arterial grafts. $J$ Card Surg. 2018;33:620-8.

17. Schwann TA, Karim A, Sleiman EH, Yammine MB, Tranbaugh RF, Engoren M, et al. The incremental value of three or more arterial grafts in coronary artery bypass grafting: the effect of native vessel disease. Ann Thorac Surg. 2018; 106:1071-8

18. Luthra S, Leiva-Juarez MM, Matuszewski M, Morgan IS, Billing JS. Does a third arterial conduit to the right coronary circulation improve survival? J Thorac Car diovasc Surg. 2018;155:855-60.

19. Grau JB, Kuschner CE, Johnson CK, Ferrari G, Zapolanski A, Brizzio ME, et al The effects of using a radial artery in patients already receiving bilateral internal mammary arteries during coronary bypass grafting: 30 day outcomes and 14 year survival in a propensity-matched cohort. Eur J Cardiothorac Surg. 2016;49: 203-10.

20. Mukherjee D, Cheryan J, Kourliouros A, Athanasio T. Does the right internal thoracic artery or saphenous vein graft offer superior revascularization of the right coronary artery? Interact Cardiovasc Thorac Surg. 2012;15:244-7.

21. Yano K, Tsubota H, Arai Y, Abe T, Hanyu M. Abdominal surgery for gastric cancer following coronary artery bypass grafting using an in situ right gastroepiploic artery graft. J Card Surg. 2017;32:538-41.

22. Saki K, Mizuno T, Watanabe T, Nagoaka E, Oi K, Yashima M, et al. Managemen of right gastroepiploic arterial coronary grafts in subsequent abdominal surgeries Ann Thorac Surg. 2018;106:52-7. 